\title{
Rejection Blues: Why Do Research Papers Get Rejected?
}

\author{
Suvarna Satish Khadilkar ${ }^{1}$
}

Received: 26 June 2018/Accepted: 26 June 2018/Published online: 5 July 2018

(C) Federation of Obstetric \& Gynecological Societies of India 2018

\begin{abstract}
About the Author

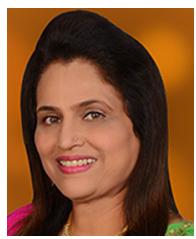

Dr. Mrs. Suvarna Satish Khadilkar is the Editor-in-chief of this journal. She is currently working as Consultant GyneEndocrinologist, Bombay Hospital Institute of Medical Sciences and Medical Research Centre, Mumbai. In the past she worked as Associate Professor and Unit Chief at JJ Group of Hospitals and Grant Medical College [GMC], Mumbai, and thereafter in the capacity of the Professor and Head in Department of Obstetrics and Gynecology, Government Medical College, Kolhapur, Maharashtra. She has been an undergraduate and postgraduate teacher and examiner, Mumbai University and Maharashtra University of Health Sciences. Pursuing her interest in endocrinology, she acquired Diploma in Endocrinology from the prestigious University of South Wales, UK, and has been appointed as a recognized teacher in endocrinology in University of South Wales. She is the Treasurer of FOGSI. She has held many prestigious positions like President of Indian Menopause Society, Chairperson of Reproductive Endocrinology Committee of FOGSI, President, Association of Medical Women in India, Mumbai. She is currently the librarian of Mumbai Ob-Gyn Society. She has published six text books and more than 70 articles at national and international levels. She is recipient of 30 awards for her research work including the Young Scientist Award.
\end{abstract}

\begin{abstract}
It is really disheartening when your paper gets rejected by a journal. Authors work very hard to conduct research. They present their work in the form of platform
\end{abstract}

Prof Suvarna Khadilkar MD DGO FICOG, CIMP, Diploma in Endocrinology (UK) is Editor in Chief of Journal of Obstetrics and Gynecology of India, and Treasurer, FOGSI, she is Consultant Gyneendocrinologist, Bombay Hospital \& Medical Research Centre, Mumbai, Former Professor and Head, Dept of ObGyn, RCSM, Government Medical College, Maharashtra and Asso. Prof. \& Unit Chief Grant Medical College and Cama \& Albless hospital, Mumbai.

Suvarna Satish Khadilkar

suvarnakhadilkar@yahoo.com;

suvarnakhadilkar2@gmail.com

1 Consultant Gyne-Endocrinologist, Bombay Hospital \& Medical Research Centre, 12 New Marine Line, Mumbai 400020, India presentation in a conference and/or as a research article for publication. When their platform presentations get applauded by the audience, researchers feel encouraged to publish it. However, it may not be appreciated by editors and reviewers when the research is submitted to a journal for publication. One should not get disappointed by rejections. Most top journals have almost $80 \%$ rejection rates. This editorial will take a brief review of reasons for rejection and advise how to deal with rejections.

\section{Introduction}

If you wish to publish good-quality articles and have faced rejections, this editorial will help you understand common reasons for rejection so that you may rectify the deficiencies before you submit your work. You stand a better 
chance of acceptance if due care is taken while preparing your manuscript. One question keeps disturbing authors of rejected papers: "If I have done a useful study and have written to the perfection and to my satisfaction, why did the editors and reviewers reject my paper?" Contrary to belief, editors don't like to reject papers. Every time I reject a paper, I appreciate the efforts that have gone in the preparation, but I also ask myself "Am I doing justice to the readers worldwide, who take out time to read our journal to learn something new to improvise the way they practice? Don't the readers deserve the best of the best research for updating their knowledge? Do they deserve the same old findings well established several times in the literature? The answer is certainly 'No'! One must remember that world's best revolutionary trials and pathbreaking research are submitted to these prestigious journals; hence, a paper of a lower quality and priority is most likely to be rejected.

\section{Why Do Papers Get Rejected?}

Let us look at the various reasons as to why the articles get rejected. After submission the article goes through an arduous journey. Readers are requested to read our first article of editorial series on medical writing in this journal [1]. The journey of the article is clearly described. At every phase of this journey, errors and deficiencies may be encountered by editors, reviewers and also the technical team. These may or may not sustain the strict scrutiny done by the board.

First hurdle is the technical scrutiny! Authors need to comply with all the requirements of the journal and submit all the supporting documents that are necessary.

Editors initially look at the title and the subject on which the research has been based. When it is not of much interest to the readership, the paper can be directly rejected at the level of editorial discussion. Such a paper may not be sent for peer review. There are many reasons why the paper will be rejected without a detailed peer reviewers' analysis.

- The paper and the subject may be out of scope and not suitable for the journal and readership

- Weak hypothesis

- Too basic research

- Poor methodology, small sample size, poor statistical analysis

- Discrepancy of authors and institutes

- Conflict of interest not declared; ethical committee permission not taken

- Informed consent of subjects not taken

- Single case reports not making a useful point (usually banking on rarity)
- The target journal may have similar research papers published or already in the process of getting published - Suspected or confirmed plagiarism.

Only those papers that withstand the initial editorial scrutiny are then sent for reviewers' opinion for detailed analysis. This reduces the burden of papers on reviewers. Hence, editors and expert reviewers can focus and give time to do detailed critical analysis of a good-quality paper. Reasons for rejection at this stage are as follows:

- Aims do not raise the right kind of questions, and background lacks clarity of thoughts

- Data are incomplete, and the methodology section has irreparable deficiencies

- Instructions to authors are not followed strictly

- Figures are of low resolution, and tables are too complicated and are not comprehendible

- Case reports lack proper documentation and follow-up information

- Discussion and conclusions do not answer the question posed in aims and objective

- There is a mismatch between the statements made in different sections of papers

- On reviewing the manuscript editors/reviewers feel that authors have not worked hard enough to improvise the presentation of the data. Authors need to revise and rerevise as many times as required to get the flawless draft of manuscript [2]

- There is an overall lack of key elements of a good research like a strong hypothesis, flawless methodology, a well-presented results and good discussion with recommendations and conclusions

- References are not as per journal style

- Poor language and many spelling and grammatical mistakes create a bad impression on the reviewers.

These reasons should be considered by authors before preparing a manuscript to reduce their papers' rejection chances.

\section{Analysis of Reasons for Rejection}

We reviewed the reasons for rejection in this journal for the benefit of aspiring authors and readers. An analysis of reasons for rejection of 400 papers submitted to this journal (Fig. 1) revealed that poor methodology, no new information, poor scientific content, reported cases not rare enough or of low priority, and similar papers existing in the literature are the top five reasons for the submission having a final disposition of rejection.

This analysis offers an insight for aspiring authors to come up with a better manuscript. However, a rejection 
Fig. 1 Analysis of reasons for rejection

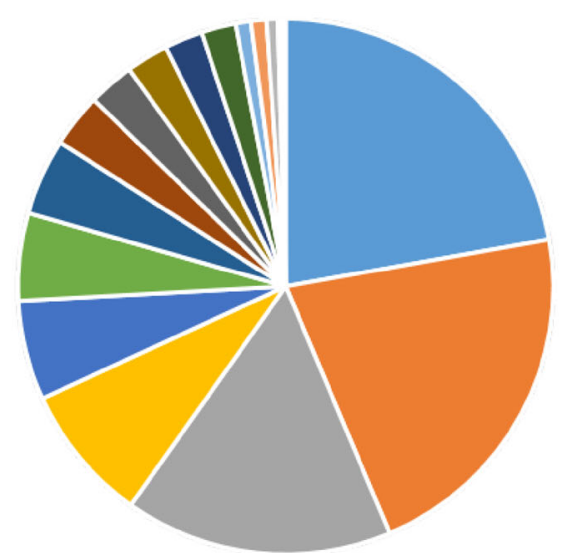

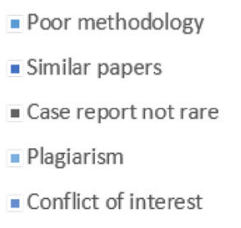

outcome doesn't always mean a poor manuscript. It could simply be less suited for the readership of the journal and be better suited to a different audience. Hence, it is important to choose the target journal wisely.

\section{Rejection Rates}

Rejection rates of various top-tier journals including ours vary between 80 and $85 \%$. Some journals have reported it to be around 90-95\% [3-5]. Sometimes restricted publishing space is given as one of the reasons for high rejection rates. But in my opinion, a good-quality research paper will find the space it deserves in top-tier journals. Interestingly, it is reported that $62 \%$ of papers have been rejected at least once by other journals before getting published [6].

\section{Paper Has Been Rejected: What Next?}

The first and foremost important step is to keep calm and not be emotional, aggressive or impulsive to write back and appeal in a fit of anger. Once rejected, most journals do not entertain any further correspondence.

Please study the reasons for rejection properly and try to rectify. They involve paper quality as well as journal suitability. It is possible that your paper is suitable for another journal. Search for another journal and submit your article. If your paper is of good quality but not suitable for that target journal, the editor himself may transfer the paper to another journal and your paper may be accepted in that journal. However, if the rejection has happened for the want of further continued research, then re-assess the paper to know if this is possible. If yes, then you need to continue the work and publish it at a later date, needless to say that next time thorough home work must be done about the target journal.

There are no secrets to success. It is the result of preparation, hard work and learning from failure.

-Colin Powell

\section{References}

1. Khadilkar SS. Journey of a research article. J Obstet Gynaecol India. 2018;68(2):75.

2. Khadilkar SS. The art and craft of making a draft: writing a goodquality scientific paper! J Obstet Gynecol India. 2018;68:151. https://doi.org/10.1007/s13224-018-1133-5.

3. The Lancet. How The Lancet handles your paper. Accessed July 2016 at: http://www.thelancet.com/lancet/information-for-autho rs/how-the-lancet-handles-your-paper.

4. The New England Journal of Medicine. Author center. Accessed July 2016 at: http://www.nejm.org/page/author-center/home.

5. The Journal of the American Medical Association. About JAMA. Accessed July 2016 at: http://jama.jamanetwork.com/public/ About.aspx.

6. Hall SA, Wilcox AJ. The fate of epidemiologic manuscripts: a study of papers submitted to epidemiology. Epidemiology. 2007;18:262-5. 